\title{
Economic Evaluation of Botulinum Toxin Versus Thoracic Sympathectomy for Palmar Hyperhidrosis: Data from a Real-World Scenario
}

\author{
Beatriz Isla-Tejera $\cdot$ Juan Ruano $\cdot$ María A. Álvarez $\cdot$ Teresa Brieva \\ Manuel Cárdenas $\cdot$ Carlos Baamonde $\cdot$ Ángel Salvatierra • \\ José-Ramón del Prado-Llergo · José C. Moreno-Giménez.
}

To view enhanced content go to www.dermtherapy-open.com

Received: March 27, 2013 / Published online: May 14, 2013

(C) The Author(s) 2013. This article is published with open access at Springerlink.com

\section{ABSTRACT}

Introduction: Local botulinum toxin injections and endoscopic thoracic sympathectomy (ETS) have shown clinical effectiveness for the treatment of palmar hyperhidrosis in several studies. Although both strategies cause considerable costs for health-care systems, at the moment there are no studies examining

B. Isla-Tejera and J. Ruano contributed equally to this work.

B. Isla-Tejera $(\varangle) \cdot$ T. Brieva · M. Cárdenas .

J.-R. del Prado-Llergo

Department of Pharmacy, Reina Sofia University

Hospital, Avda. Menéndez Pidal s/n,

14004 Córdoba, Spain

e-mail: beatrizislatj@gmail.com

J. Ruano · M. A. Álvarez · J. C. Moreno-Giménez. Department of Dermatology,

Reina Sofia University Hospital,

Córdoba, Spain

C. Baamonde · Á. Salvatierra

Department of Thoracic Surgery,

Reina Sofia University Hospital, Córdoba, Spain

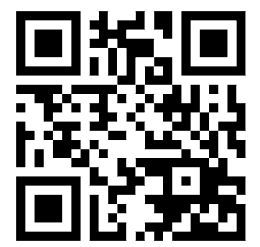

Enhanced content for this article is available on the journal web site: www.dermtherapy-open.com directly their cost-effectiveness performance. The aim of the study was to assess the incremental cost-effectiveness of botulinum toxin when compared with ETS for palmar hyperhidrosis.

Materials and Methods: Costs, effectiveness, and incremental cost-effectiveness ratio (ICER) were calculated. Costs were assessed from a Spanish National Health System perspective in a historical cohort of patients with palmar hyperhidrosis attending a tertiary referral hospital. Effectiveness was evaluated by using the Hyperhidrosis Disease Severity Scale (HDSS). A responder was defined as a patient who reported at least a two-grade improvement on the HDSS scale with respect to the baseline value. The horizon of time was 1 year.

Results: Effectiveness was greater for ETS $(n=128)$ when compared with botulinum toxin $(n=100)$ for the treatment of palmar hyperhidrosis $(92 \%$ vs. $68 \%$; odds ratio $(\mathrm{OR})=6.22[2.80,13.80]$; absolute risk ratio $(\mathrm{ARR})=-0.24[-0.45,-0.14]$; number-neededto-treat $(\mathrm{NNT})=-4 \quad[-2,-11])$. Botulinum toxin had an ICER of $125 €$ when compared with ETS during the first year of treatment.

Conclusions: In this retrospective real-world observational sample of patients with palmar 
hyperhidrosis, treatment with ETS appears to be more effective and less costly when compared with botulinum toxin during the first year of treatment. Analyses such as this give decision makers the tools to choose a better treatment option which is both highly effective and yet has a low cost.

Keywords: Botulinum toxin; Endoscopic thoracic sympathectomy; Incremental cost-effectiveness analysis; Palmar hyperhidrosis

\section{INTRODUCTION}

Primary palmar hyperhidrosis can cause occupational, social, and emotional problems that affect physical and mental well-being and usually lead to diminished quality of life [1]. Two of the treatment options currently considered as being most effective for this condition are periodical local injections of botulinum toxin and endoscopic thoracic sympathectomy (ETS) [2, 3]. At present, there are no guidelines for the clinical use of these treatment modalities for palmar hyperhidrosis. In most cases, botulinum toxin and ETS are contemplated only when the less invasive medical treatments, such as topical or systemic medications (including glycopyrrolate and clonidine) and iontophoresis, have failed to provide adequate control of hyperhidrosis [4-8].

Studies directly comparing the effectiveness of botulinum toxin and ETS for palmar hyperhidrosis are scarce [9]. Recently, our group has observed that ETS is superior to botulinum toxin in the treatment of palmar hyperhidrosis in terms of efficacy and patient satisfaction, particularly in subjects with baseline severe palmar hyperhidrosis [10]. However, as yet there are no published studies that analyze the economic impact of both treatments. We believe that such an analysis is necessary, particularly because of the high cost associated with both treatments. Regardless of perspective, the objective of such an evaluation would be to provide information on the clinical and economic consequences related to these therapeutic alternatives faced by patient/ physician. From an economic standpoint, an outcomes analysis may provide general evidence that could guide future research efforts by identifying decision-critical parameters that help to indicate the best way to treat palmar hyperhidrosis.

Therefore, the aim of this study was to evaluate the cost (expressed in monetary terms), with regard to efficiency and patientreported outcomes, between botulinum toxin and ETS in the treatment of palmar hyperhidrosis in a real-world scenario.

\section{MATERIALS AND METHODS}

\section{Population and Design}

Following a retrospective and observational design, an economic evaluation was performed comparing the cost-efficacy of botulinum toxin versus ETS in palmar hyperhidrosis. Candidates were consecutive patients with idiopathic palmar hyperhidrosis treated with either one of these two techniques between January 2005 and December 2010 in the Department of Dermatology and Thoracic Surgery of the Reina Sofia University Hospital (Córdoba, Spain).

Our hospital protocols for these treatments were followed in all cases. Prior to treatment with botulinum toxin, patients underwent nerve block anesthesia of the median, radial, and ulnar nerves with $0.5 \%$ bupivacaine injected into the wrist. Botulinum toxin A 
(Botox Cosmetic ${ }^{\circledR}$, Allergan Pharmaceuticals, Westport, Ireland), $100 \mathrm{IU}$, was diluted in $5 \mathrm{~mL}$ of $0.9 \%$ saline. Guided by a $1-\mathrm{cm}^{2}$ grid drawn on a transparent dressing (Tegaderm $^{\circledR}, 3 \mathrm{M}$ Health Care, Neuss, Germany) covering the palm, $0.1 \mathrm{~mL} /$ grid cell was injected using a 30-G needle, avoiding the thenar eminence; $0.1 \mathrm{~mL}$ was injected into each phalanx, except the first phalanx of the thumb, which was left free of toxin. A total of $100 \mathrm{IU}$ of botulinum toxin was injected into each hand.

Endoscopic thoracic sympathectomy was performed in all cases under general anesthesia with double lumen intubation. The patient was placed in the semi-prone, anti-Trendelenburg position. The material was inserted through two openings, one located in the fourth intercostal space in the mid-axillary line and the other in the third space before the axillary line. The sympathetic chain was interrupted, with an endoscopic diathermy hook, at different levels depending on the location of the hyperhidrosis (exclusively palmar or mixed) (Table 1). In each case, we cauterized the ganglion over the neck of the rib with coagulation diathermy from the superior edge of the rib to just above the inferior edge. The patient was kept under observation in the ambulatory major surgery unit, and was discharged on the same day if no postoperative complications occurred. All patients were

Table 1 Levels of resection of the sympathetic chain

\begin{tabular}{lllll}
\hline Resection & Levels & Total & $\begin{array}{l}\text { Palmar } \\
(\mathbf{C H})\end{array}$ & $\begin{array}{l}\text { Palmar + } \\
\text { axilar } \\
(\mathbf{C H})\end{array}$ \\
\hline Including T2 & T2 & $2(1.5 \%)$ & $2(0)$ & $2(2)$ \\
& T2T3 & $13(10.3 \%)$ & $16(16)$ & $8(6)$ \\
& T2T4 & $32(25.4 \%)$ & $34(30)$ & $26(2)$ \\
& Total & 47 & $52(46)$ & $36(10)$ \\
Including T3 & T3 & $18(14.3 \%)$ & $30(24)$ & $2(2)$ \\
& T3T4 & $26(20.6 \%)$ & $21(2)$ & $24(6)$ \\
& T3T5 & $6(4.7 \%)$ & $4(2)$ & $6(6)$ \\
& Total & 50 & $55(28)$ & $32(14)$ \\
No data & & $29(23.2 \%)$ & $17(16)$ & $12(10)$ \\
\hline
\end{tabular}

$\mathrm{CH}$ compensatory hyperhidrosis informed of the risks and side effects and gave their written informed consent before treatment.

\section{Data Source}

Socio-demographic and clinical information about patients was collected from computerized medical records and a telephone survey. The survey contained questions about the baseline situation (family medical history and locations of compensatory hyperhidrosis and its severity) and post-treatment situation (hyperhidrosis severity, patient satisfaction, and associated side effects). The cost considered for botulinum toxin was the manufacturer's selling price stated in the Spanish Catalogue of Pharmaceutical Specialties plus VAT [6] (Table 2). Unit costs per ETS and stay costs for a 4-hour-a-day hospital admission were obtained from the Reina Sofia University Hospital's economic management database.

\section{Evaluation of Effectiveness and Patient Satisfaction}

Effectiveness was evaluated by estimating hyperhidrosis severity at baseline and after treatment using the Hyperhidrosis Disease Severity Scale (HDSS) [11]. The patient is asked to select the statement that best reflects his or her experience with sweating of the specified body area (Table 3). Next to each statement, there is a number that indicates how responses should be scored. This validated scale offers a quick and easy subjective way to measure the severity of hyperhidrosis according to how it affects daily life. A score of 1 or 2 indicates mildto-moderate hyperhidrosis, and 3 or 4 severe hyperhidrosis. Post-treatment, as part of a subjective efficacy evaluation and patient satisfaction, the HDSS is administered again. An improvement of 1 or 2 points on the HDSS scale represents a reduction in sweat production 
Table 2 Sources for valuation of unit costs associated with botulinum toxin and endoscopic thoracic sympathectomy

\begin{tabular}{|c|c|c|c|}
\hline & $\begin{array}{l}\text { Cost } \\
\text { hour }^{-1}(€)\end{array}$ & $\begin{array}{l}\text { Time } \\
(\mathrm{h})\end{array}$ & $\begin{array}{l}\text { Cost } \\
\operatorname{session}^{-1}(€)\end{array}$ \\
\hline \multicolumn{4}{|l|}{ ETS } \\
\hline Operating room ${ }^{\mathrm{a}}$ & 453.13 & 1 & 453.13 \\
\hline Thoracic surgeon & 286.67 & 1 & 286.67 \\
\hline Anesthetist & 237.04 & 1 & 237.04 \\
\hline $\begin{array}{l}\text { Ambulatory major } \\
\text { surgery unit }\end{array}$ & 103.25 & 1.5 & 154.88 \\
\hline Total & - & - & $1,131.72$ \\
\hline \multicolumn{4}{|l|}{ Botulinum toxin } \\
\hline $\begin{array}{l}\text { Drug } \\
\qquad(\text { PTR + VAT })\end{array}$ & 140.66 & 2 & 281.32 \\
\hline Operating room ${ }^{\mathrm{a}}$ & 453.14 & 0.5 & 226.57 \\
\hline Dermatologist & 152.20 & 0.5 & 76.10 \\
\hline Total & - & - & 583.99 \\
\hline
\end{tabular}

ETS endoscopic thoracic sympathectomy; PTR price to retailer

${ }^{a}$ Fungible and nursery cost are included

of $50 \%$ or $80 \%$, respectively. Unlike gravimetric methods of measuring sweat production, it is easy to use, making it ideal for use with telephone surveys. Absolute pre-treatment HDSS (HDSSpre), post-treatment HDSS (HDSSpost), and incremental effectiveness (HDSSdif) were evaluated. Patient satisfaction was measured on a continuous numerical scale from 0 to 10 , with 0 representing "totally dissatisfied" and 10 "totally satisfied".

\section{Cost-Effectiveness Analysis}

A responder was defined as a patient who reported at least a two-degree improvement on the HDSS scale with respect to the baseline value. Both absolute and incremental effectiveness were determined for both modalities of treatment. Incremental cost per additional responder (ICER) following botulinum toxin compared to ETS was calculated. In addition, the annual per-patient cost/HDSSdif ratio and cost/satisfaction ratio were calculated. A descriptive temporal analysis for each year over a 5-year period for these parameters was performed. Analyses included only direct costs (drug and health resources). Since the maximum number of sessions with botulinum toxin per year was two and the ratio between the costs of ETS and one toxin session was close to two, we established 1 year as the time horizon for the economic analysis. The study was conducted from the perspective of the Spanish National Health System. All costs are shown in Euros $(€)$ and updated to June 2011.

\section{Statistical Analysis}

The normality of the data was assessed using the Shapiro-Wilk test; logarithmic transformation was used when variables did not have a normal distribution. To check for differences between the two treatment groups, the Chi-square test was used for qualitative variables and the Student's $t$ test for quantitative variables. All the data presented in the text, tables, and graphs are expressed as mean and standard deviation (SD), unless otherwise specified. We considered a 95\% confidence interval for the mean and a $P$ value of less than 0.05 as statistically significant. All tests were performed with different packages of the $\mathrm{R}$ statistical programming environment (GNU) [12].

All procedures were performed in accordance with the ethical standards of the responsible committee on human experimentation and with the Declaration of Helsinki of 1975. Informed consent was obtained from all the patients included in the study. 
Table 3 Hiperhidrosis Disease Severity Scale (HDSS) score system

\begin{tabular}{lc}
\hline $\begin{array}{l}\text { "How would you rate the severity of your } \\
\text { hyperhidrosis?” }\end{array}$ & Score \\
\hline $\begin{array}{l}\text { My sweating is never noticeable and never } \\
\text { interferes with my daily activities }\end{array}$ & 1 \\
$\begin{array}{l}\text { My sweating is tolerable but sometimes interferes } \\
\text { with my daily activities }\end{array}$ & 2 \\
$\begin{array}{l}\text { My sweating is barely tolerable and frequently } \\
\text { interferes with my daily activities }\end{array}$ & 3 \\
$\begin{array}{l}\text { My sweating is intolerable and always interferes } \\
\text { with my daily activities }\end{array}$ & 4 \\
\hline
\end{tabular}

\section{RESULTS}

\section{Baseline Characteristics of the Study Groups}

Of a total of 345 candidates, only 228 patients were included for subsequent analysis-161 women and 67 men aged $28.2 \pm 10.3$ yearssince no information could be obtained from the other patients by telephone survey. When efficacy and patient satisfaction were assessed, an average of 3.69 years had elapsed since treatment. Analysis of the differences between the two treatments (Table 4) revealed that the severity of hyperhidrosis was greater $(P=0.0017)$ in patients undergoing ETS $(n=128)$ compared to those who opted for botulinum toxin $(n=100)$. Nonetheless, efficacy $(P<0.001)$ and patient satisfaction $(P<0.001)$ were greater after endoscopic surgery. No significant differences were observed for the other variables analyzed.

\section{Descriptive Temporal Analysis}

The temporal analysis of efficacy, satisfaction, security, and costs by year over the first 5 years of use of both treatments in our hospital is shown in Tables 5 and 6, and Fig. 1. Efficacy and satisfaction increased progressively after the first year of treatment in both groups. Dropouts in the botulinum toxin group appeared mainly during the first year, generally due to lack/loss of efficacy or to adverse effects, in most cases transitory and associated with the technique.

When both modalities of treatment are compared by considering annual per-patient value of cost/HDSSdif and cost/satisfaction ratios, ETS yields lower values than botulinum toxin for both ratios during the first year. As of

Table 4 Descriptive analysis of the study group of patients with palmar hyperhidrosis treated with either botulinum toxin or endoscopic thoracic sympathectomy

\begin{tabular}{llll}
\hline & Botulinum toxin $(\boldsymbol{n}=\mathbf{1 0 0})$ & Sympathectomy $(\boldsymbol{n}=\mathbf{1 2 8})$ & $\boldsymbol{P}$ \\
\hline Gender (men/women) & $26 / 74$ & $41 / 87$ & n.s. $^{\mathrm{a}}$ \\
Age (years) & $27.7(12-55)$ & $28.8(13-56)$ & n.s. $^{a}$ \\
Family medical history & $39(39 \%)$ & $52(40.6 \%)$ & n.s. $^{{ }^{a}}$ \\
HDSSpre & $3.48(2-4)$ & $3.73(2-4)$ & $0.0017^{\mathrm{b}}$ \\
HDSSpost & $1.71(1-4)$ & $1.12(1-3)$ & $<0.001^{\mathrm{b}}$ \\
Patient satisfaction & $6.66(2.81)$ & $8.16(2.60)$ & $<0.001^{\mathrm{b}}$ \\
\hline
\end{tabular}

HDSSpost HDSS post-treatment, HDSSpre HDSS pre-treatment, n.s. non significant

a Chi-square analysis with Yates' correction

b Kruskall-Wallis test 
Table 5 Descriptive temporal analysis for the treatment of palmar hyperhidrosis with botulinum toxin

\begin{tabular}{|c|c|c|c|c|c|}
\hline Duration of treatment (years) & $1 n=66$ & $2 n=18$ & $3 n=10$ & $4 n=4$ & $5 n=2$ \\
\hline Gender (men/women) & $19 / 47$ & $2 / 16$ & $2 / 8$ & $2 / 2$ & $1 / 1$ \\
\hline Age (years) & $29 \pm 10$ & $26 \pm 11$ & $23 \pm 5$ & $25 \pm 10$ & $17 \pm 1$ \\
\hline HDDSpre & $3.41 \pm 0.63$ & $3.56 \pm 0.51$ & $3.60 \pm 0.52$ & $3.75 \pm 0.50$ & $4.00 \pm 0.00$ \\
\hline HDDSpost & $1.83 \pm 0.97$ & $1.50 \pm 0.62$ & $1.60 \pm 0.84$ & $1.00 \pm 0.10$ & $1.50 \pm 0.71$ \\
\hline HDDSdif $^{a}$ & $1.58 \pm 1.02$ & $2.06 \pm 0.54$ & $2.00 \pm 0.67$ & $2.75 \pm 0.50$ & $2.50 \pm 0.71$ \\
\hline Satisfaction & $6.1 \pm 3.1$ & $7.3 \pm 2.1$ & $8.4 \pm 0.8$ & $8.7 \pm 1.5$ & $10.0 \pm 0.0$ \\
\hline Adverse events & 38 & 14 & 8 & 4 & 1 \\
\hline Transitory/permanent & $34 / 4$ & $14 / 0$ & $8 / 0$ & $4 / 0$ & $1 / 0$ \\
\hline Weakness & 31 & 14 & 7 & 4 & 0 \\
\hline Paresthesias & 2 & 1 & 0 & 1 & 0 \\
\hline Hematoma & 2 & 0 & 0 & 0 & 0 \\
\hline Pain & 9 & 0 & 1 & 0 & 1 \\
\hline Dropouts & 36 & 6 & 0 & 1 & 0 \\
\hline Hyperhidrosis cessation & 1 & 0 & 0 & 0 & 0 \\
\hline Lack/loss efficacy & 23 & 4 & 0 & 0 & 0 \\
\hline Adverse events & 5 & 1 & 0 & 1 & 0 \\
\hline Others & 7 & 1 & 0 & 0 & 0 \\
\hline Total cost $(€)$ & 77,088 & 21,024 & 11,680 & 4,672 & 2,336 \\
\hline Cost year ${ }^{-1}$ patient $^{-1}(€)$ & 1,168 & 1,168 & 1,168 & 1,168 & 1,168 \\
\hline Cost $\operatorname{HDSSdif}^{-1}(€)$ & $701.4 \pm 153.1$ & $616.4 \pm 106.8$ & $661.8 \pm 139.2$ & $438.2 \pm 48.6$ & $486.6 \pm 68.8$ \\
\hline Cost satisfaction $^{-1}(€)$ & $578.8 \pm 252.4$ & $476.8 \pm 149.4$ & $353.6 \pm 17.5$ & $343.4 \pm 21.2$ & $294.4 \pm 0.00$ \\
\hline
\end{tabular}

HDSSpre HDSS pre-treatment; HDSSpost HDSS post-treatment

${ }^{\mathrm{a}}$ HDSSdif $=[$ HDSSpost - HDSSpre $]$

this moment, an overlapping effect is observed between ETS cost/HDSSdif ratio and botulinum toxin cost/satisfaction ratio (Fig. 1).

\section{Incremental Cost-effectiveness Analysis}

In the course of the 5-year study period, total costs associated with palmar hyperhidrosis treatment at Reina Sofia University Hospital were $€ 178,704.00$ for botulinum toxin and $€ 144,896.00$ for ETS (Tables 5, 6). There are statistically significant differences in the reduction of HDSS and degree of satisfaction when botulinum toxin is compared with ETS (all $P<0.05$ ) (Table 4). The incremental cost per additional responder following treatment with botulinum toxin was $€ 125$ higher than after ETS during the first year (Table 7). As the number-needed-to-treat (NNT) value shows, four patients have to be treated with botulinum toxin to obtain the same rate of effectiveness that is achieved with ETS (Table 8). 


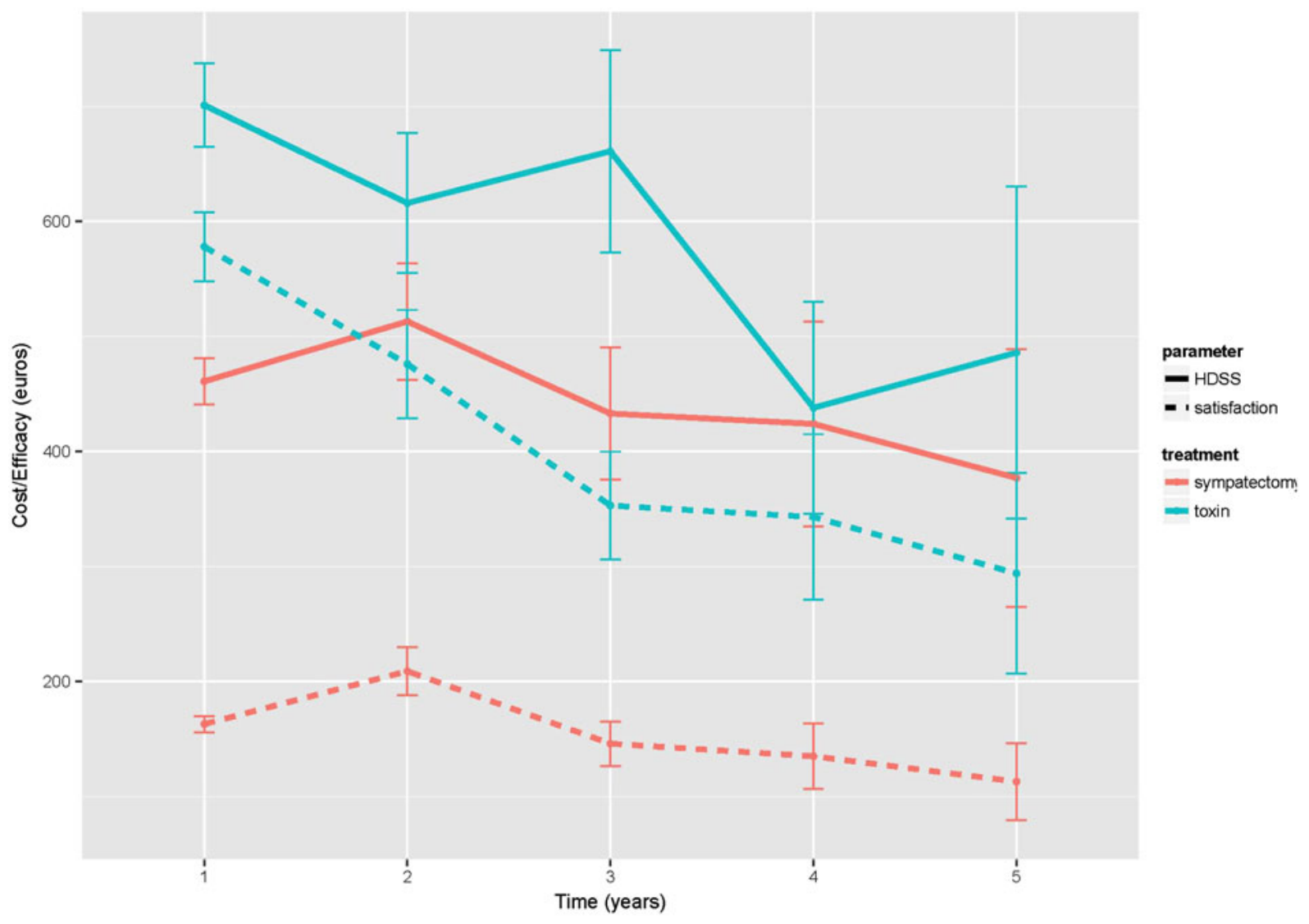

Fig. 1 Temporal analysis of cost/HDSS and cost/satisfaction ratios comparing botulinum toxin versus endoscopic thoracic sympathectomy for the treatment of palmar hyperhidrosis

\section{DISCUSSION}

In our study, ETS for palmar hyperhidrosis appears to be more effective and less costly than botulinum toxin during the first year of treatment. Botulinum toxin was associated with higher total costs and less effectiveness than ETS in a 5-year palmar hyperhidrosis treatment program in our hospital. When cost/HDSSdif and cost/satisfaction ratios are evaluated over 5 years, ETS-associated cost/satisfaction and botulinum toxin-associated cost/HDSSdif were the lower and the higher values, respectively. Cost/HDSSdif and cost/satisfaction ratios represent how much money, on average, is required to improve one unit of HDSS or to increase one level in the satisfaction scale, respectively, per patient and year, for each modality of treatment. Hence, we may conclude that increasing the satisfaction of these patients by ETS is the cheapest strategy, and that the most expensive approach is to reduce sweating severity by means of botulinum toxin injections. Considering that four patients have to be treated with botulinum toxin to obtain the same rate of effectiveness that is achieved with ETS, and that the ICER for botulinum toxin was $€ 125$, this gives a potential saving of $€ 3,125$ if ETS had been chosen by all patients. This saving accounts for $2.93 \%$ of the ETS-associated total cost during the first year of the study. 
Table 6 Descriptive temporal analysis for the treatment of palmar hyperhidrosis with endoscopic thoracic sympathectomy

\begin{tabular}{|c|c|c|c|c|c|}
\hline Duration of treatment (years) & $1 n=94$ & $2 n=18$ & $3 n=10$ & $4 n=4$ & $5 n=2$ \\
\hline Gender (men/women) & $31 / 63$ & $7 / 11$ & $2 / 8$ & $0 / 4$ & $1 / 1$ \\
\hline Age (years) & $28 \pm 9$ & $33 \pm 10$ & $32 \pm 12$ & $17 \pm 1$ & $20 \pm 3$ \\
\hline HDDSpre & $3.71 \pm 0.54$ & $3.78 \pm 0.43$ & $3.70 \pm 0.48$ & $3.75 \pm 0.50$ & $4.00 \pm 0.00$ \\
\hline HDDSpost & $1.11 \pm 0.37$ & $1.28 \pm 0.57$ & $1.00 \pm 0.00$ & $1.00 \pm 0.00$ & $1.00 \pm 0.00$ \\
\hline HDDSdif $^{a}$ & $2.61 \pm 0.69$ & $2.50 \pm 0.71$ & $2.70 \pm 0.48$ & $2.75 \pm 0.50$ & $3.00 \pm 0.00$ \\
\hline Satisfaction & $8.1 \pm 2.6$ & $8.2 \pm 2.7$ & $8.5 \pm 2.2$ & $8.5 \pm 1.3$ & $10.0 \pm 0.0$ \\
\hline Adverse events & 80 & 18 & 10 & 4 & 2 \\
\hline Compensatory hyperhidrosis & 77 & 18 & 10 & 4 & 2 \\
\hline Transitory pain & 8 & 5 & 1 & 1 & 0 \\
\hline Permanent pain & 3 & 0 & 0 & 0 & 0 \\
\hline Neurapraxia & 4 & 0 & 0 & 0 & 0 \\
\hline Others & 8 & 0 & 0 & 1 & 0 \\
\hline Total cost $(€)$ & 106,408 & 20,376 & 11,320 & 4,528 & 2,264 \\
\hline Cost year $^{-1}$ patient $^{-1}(€)$ & 1,132 & 1,132 & 1,132 & 1,132 & 1,132 \\
\hline Cost HDSSdif ${ }^{-1}(€)$ & $461.3 \pm 179.9$ & $513.5 \pm 240.4$ & $433.9 \pm 91.1$ & $424.4 \pm 94.3$ & $377.3 \pm 0.0$ \\
\hline Cost satisfaction $^{-1}(€)$ & $163.2 \pm 154.5$ & $209.4 \pm 253.2$ & $146.8 \pm 59.1$ & $135.5 \pm 20.9$ & $113.2 \pm 0.0$ \\
\hline
\end{tabular}

HDSSpost HDSS post-treatment; HDSSpre HDSS pre-treatment

${ }^{a}$ HDSSdif $=[$ HDSSpost - HDSSpre $]$

Table 7 Incremental cost-effectiveness ratio of botulinum toxin versus endoscopic thoracic sympathectomy for the treatment of palmar hyperhidrosis

\begin{tabular}{lccc}
\hline $\begin{array}{l}\text { Comparative treatment } \\
\text { modalities }\end{array}$ & $\begin{array}{l}\text { Incremental } \\
\text { cost }(\boldsymbol{\epsilon})\end{array}$ & $\begin{array}{l}\text { Incremental } \\
\text { effectiveness }\end{array}$ & $\begin{array}{l}\text { ICER } \\
(\boldsymbol{\epsilon})^{\mathbf{a}}\end{array}$ \\
\hline $\begin{array}{l}\text { Botulinum toxin (A) vs. } \\
\text { ETS (B) }\end{array}$ & 30.26 & 0.24 & 125.00 \\
\hline $\begin{array}{l}\text { ICER } \text { Incremental } \operatorname{cost}_{\text {effectiveness ratio }} \\
{ }^{a} \text { ICER }=\left(\text { total } \operatorname{cost}_{\mathrm{A}}-\text { total } \operatorname{cost}_{\mathrm{B}}\right) /\left(\text { effectiveness }_{\mathrm{B}}-\text { effectiveness }_{\mathrm{A}}\right)\end{array}$
\end{tabular}

One of the benefits of using real-world data is that they can provide estimates of long-term effectiveness in a variety of typical practice settings when multiple alternative interventions or clinical strategies are compared in a diverse study population, which reflects the range and distribution of patients observed in clinical practice [13]. This reinforces the applicability of our results to similar populations as it reduces uncertainty in the clinical practice decision-making process when estimates of pharmacoeconomic studies relying on clinical trial data are used.

However, various aspects related to the study design should be taken into account when evaluating the results. Thus, the single-center retrospective design used may have detracted from the representativeness of the results through the effect of inaccuracies in the patients' clinical histories and telephone survey. This potential bias, inherent in most retrospective work, is a result of the lack of welldefined standards for visit recording and of clinical practice variability-two distinct features of clinical trial designs. In any event, our results could be validated by a future 
Table 8 Cost analysis of the treatment with botulinum toxin or endoscopic thoracic sympathectomy for palmar hyperhidrosis

\begin{tabular}{llllllll}
\hline Treatment & $\boldsymbol{n}$ & HDSSdif $>\mathbf{2}^{\mathbf{a}}$ & Odds & OR & ARR & RRR & NNT \\
\hline $\begin{array}{l}\text { Botulinum } \\
\text { toxin }\end{array}$ & 100 & 68 & 0.68 & 1 & - & - & \\
ETS & & & {$[0.58,0.76]$} & & & & \\
& 128 & 119 & 0.92 & 6.22 & -0.25 & -0.36 & -4 \\
& & & {$[0.87,0.96]$} & {$[2.80,13.80]$} & {$[-0.35,-0.14]$} & {$[-0.57,-0.18]$} & {$[-3,-7]$} \\
\hline
\end{tabular}

$A R R$ absolute risk reduction; ETS endoscopic thoracic sympathectomy; HDSSpost HDSS post-treatment; HDSSpre HDSS pre-treatment; $N N T$ number-needed-to-treat; $O R$ Odds ratio; $R R R$ relative risk reduction

${ }^{\mathrm{a}}$ HDSSdif $=[$ HDSSpost - HDSSpre $]$

standardized, multi-center, prospective study. Secondly, the initial and final measurement of the severity of hyperhidrosis was made retrospectively, thus raising the possibility of a recall bias. However, since hyperhidrosis is a lengthy process with an evolutionary period of over 10 years in most cases, we believe that patients recall the effects produced by palmar hyperhidrosis before and after they underwent treatment with sufficient precision.

One other potential shortcoming of our study was excluding costs arising from the management of adverse reactions associated with each treatment. A treatment may be more expensive, but by being more effective or involving less complications/sequelae, it may be preferable for the patient. We consider necessary that patient should take into account this vital information when choosing one of these therapeutic options. In the group of patients treated with ETS, both patient satisfaction and efficacy were clearly conditioned by the occurrence of compensatory hyperhidrosis $(\mathrm{CH}) . \mathrm{CH}$ is the most common side effect of ETS, as well as the most disabling side effect when it is severe [14]. The fact that the efficacy of this procedure is conditioned by the severity of $\mathrm{CH}$, when the two measures should be independent, helps to explain the impact of this side effect on subjects who undergo surgery. These patients would probably be willing to accept this side effect if it were offset by a significant improvement in palmar hyperhidrosis. This could explain why greater satisfaction is seen in this group despite the higher incidence of $\mathrm{CH}$ after ETS. The frequency of the rest of the adverse reactions, such as pain, weakness, or hematoma was minor, mostly transitory, and with difficult-toestimate derived costs.

In summary, our data suggest that when considering therapeutic options for palmar hyperhidrosis, ETS may offer greater efficacy, greater patient satisfaction, and lower direct cost than botulinum toxin. In the virtual absence of similar economic studies, this study can be used as an additional source of information for placing both options within the scope of the Spanish National Health System.

\section{ACKNOWLEDGMENTS}

María A. Álvarez is the guarantor for this article and takes responsibility for the integrity of the work as a whole. No funding was involved in this study or the development of the manuscript.

Conflict of interest. Beatriz Isla-Tejera, María A. Álvarez, Juan Ruano, Teresa Brieva, Manuel Cárdenas, Carlos Baamonde, Ángel 
Salvatierra, Jose-Ramón del Prado-Llergo, and José C. Moreno-Giménez declare that they have no conflict of interest.

Compliance with Ethics Guidelines. All procedures were performed in accordance with the ethical standards of the responsible committee on human experimentation and with the Declaration of Helsinki of 1975. Informed consent was obtained from all the patients included in the study.

Open Access. This article is distributed under the terms of the Creative Commons Attribution Noncommercial License which permits any noncommercial use, distribution, and reproduction in any medium, provided the original author(s) and the source are credited.

\section{REFERENCES}

1. Cetindag IB, Boley TM, Webb KN, Hazelrigg SR. Long-term results and quality-of-life measures in the management of hyperhidrosis. Thorac Surg Clin. 2008;18:217-22.

2. Shelley WB, Talanin NY, Shelley ED. Botulinum toxin therapy for palmar hyperhidrosis. J Am Acad Dermatol. 1998;38:227-9.

3. Ito K, Yanagishita $\mathrm{T}$, Ohshima $\mathrm{Y}$, Tamada $\mathrm{Y}$, Watanabe D. Therapeutic effectiveness of botulinum toxin type A based on severity of palmar hyperhidrosis. J Dermatol. 2011;38:859-63.

4. Solish N, Bertucci V, Dansereau A, et al. A comprehensive approach to the recognition, diagnosis, and severity-based treatment of focal hyperhidrosis: recommendations of the Canadian Hyperhidrosis Advisory Committee. Dermatol Surg. 2007;33:908-23.
5. Chia HY, Tan AS, Chong WS, Tey HL. Efficacy of iontophoresis with glycopyrronium bromide for treatment of primary palmar hyperhidrosis. J Eur Acad Dermatol Venereol. 2012;26:1167-70.

6. Hoorens I, Ongenae K. Primary focal hyperhidrosis: current treatment options and a step-by-step approach. J Eur Acad Dermatol Venereol. 2012;26:1-8.

7. Abell E, Morgan K. The treatment of idiopathic hyperhidrosis by glycopyrronium bromide and tap water iontophoresis. Br J Dermatol. 1974;91:87-91.

8. Walling HW, Swick BL. Treatment options for hyperhidrosis. Am J Clin Dermatol. 2011;12:285-95.

9. Ambrogi V, Campione E, Mineo D, Paternò EJ, Pompeo E, Mineo TC. Bilateral thoracoscopic T2 to T3 sympathectomy versus botulinum injection in palmar hyperhidrosis. Ann Thorac Surg. 2009;88:238-45.

10. Álvarez M, Ruano J, Gómez F, et al. Differences between objective efficacy and perceived efficacy in patients with palmar hyperhidrosis treated with either botulinum toxin or endoscopic thoracic sympathectomy. J Eur Acad Dermatol Venereol. 2012;27:e282-8.

11. Strutton DR, Kowalski JW, Glaser DA, Stang PE. US prevalence of hyperhidrosis and impact on individuals with axillary hyperhidrosis: results from a national survey. J Am Acad Dermatol. 2004;51:241-8.

12. $\mathrm{R}$ Development Core Team. $\mathrm{R}$ Foundation for Statistical Computing. R: a language and environment for statistical computing [Internet]. Vienna; 2012. http://www.r-project.org/ (Accessed 12 Oct 2012).

13. Steele T, Pawaskar M, Balkrishnan R, Fleischer A, Feldman SR. Does cost-effectiveness play a role in clinical trials? Dermatol Ther. 2007;20:110-9.

14. Dewey TM, Herbert MA, Hill SL, Prince SL, Mack MJ. One-year follow-up after thoracoscopic sympathectomy for hyperhidrosis: outcomes and consequences. Ann Thorac Surg. 2006;81:1227-32 (discussion 1232-3). 